UDK 875.11 Žebre D.

Karmen Salmič Kovačič

Univerzitetna knjižnica, Maribor

University Library, Maribor

\title{
Strukturna funkcija teksture v Žebretovi skladbi Svobodi naproti
}

\author{
The Structural Function of Texture in \\ Žebre's Composition Towards Liberty
}

Ključne besede: glasbena analiza, strukturne funkcije, tekstura, Demetrij Žebre

\section{Povzetek}

V članku predstavljena analiza teksture v skladbi Svobodi naproti (1944) Osterčevega učenca in slovenskega medvojnega modernista Demetrija Žebreta temelji na teoriji strukturnih funkcij v glasbi Wallaca Berryja. Njeno osrednje izhodišče je predpostavka, da so v komponirani glasbi ( $\mathrm{v}$ nasprotju z glasbo slučajnosti) akcije (spremembe, dogodki) znotraj posameznih elementov struktur (linije tonske višine, tonalna in harmonska zaporedja, ritem, metrum, tekstura in barva) zasnovane in kontrolirane tako, da na različnih hierarhičnih râvneh sooblikujejo (s komplementarnim ali kompenzacijskim učinkom) procese naraščanja napetosti, sproščanja in statičnosti, s katerimi pri poslušalcu vzbujajo analogne občutke. Zato je najprej opisana krivulja spreminjanja napetosti v skladbi, ki je nastala na temelju slušne izkušnje in notnega zapisa. Analiza je osredotočena na strukturno vlogo teksture v progresivno-recesivnem gibanju glasbenega toka, pred tem pa so predstavljene bistvene Berryjeve trditve in njegova definicija tega strukturnega elementa $\mathrm{z}$ določitvijo in opisi posameznih teksturnih parametrov, ki se v naši in tuji analitični praksi šele uveljavljajo.
Keywords: music analysis, structural functions, texture, Demetrij Žebre

\section{SUMMARY}

The article presents an analysis based on the theory of structural functions in music by Wallace Berry of the composition Towards Liberty (1944), written by Osterc's student and Slovenian modernist in the period between the World Wars, Demetrij Žebre. Its point of departure lies in the hypothesis that, in composed music (contrary to chance music), actions (changes, events) within individual elements or rather structures (the line of successive pitches, tonal and harmonic progressions, rhythm, metre, texture, and colour) are conceived and controlled in such a way that, on various hierarchical levels (through complementary or compensatory effects), they take part in processes in progression toward intensity, in recessive actions of relaxation, and in sections of stasis, all of which arouses analogous sensations with the listener. The curve of changes in intensity, realized on the basis of listening and of studying the score, is described first. The analysis focuses on the structural role of texture in the progressive/recessive flow of music, after Berry's assertions and his definition of this structural element have been presented, together with the description of individual textural parameters that are only just winning recognition in analytical practice at home and abroad. 


\section{Uvod}

Bistveno vprašanje, ki se je sprožilo ob nameri kakršnekoli analize glasbenega stavka, pa ne le Žebretovih skladb, je bilo metodološko - kaj opazovati, opisovati, analizirati, klasificirati, interpretirati v glasbi in kako. Predvsem pa, kako, da bo o glasbi nekaj povedanega, nekaj več od ločenega opisovanja oziroma "seciranja" skladbe na posamezne strukturne elemente - melodiko, ritem, harmonijo itd., in brez prave predstave o tem, kako so ti med seboj povezani ter vsaj približne predstave o tem, kako glasba zveni. Med prebiranjem množice glasbeno-analitičnih metod in teorij se je vedno bolj porajala nevarnost oddaljevanja od osnovne namere, nevarnost v poglabljanje "analize" analiz, želja po poznavanju vse večjega števila možnosti ter razbiranju koristnih in v konkretnem primeru uporabnih drobcev. V tovrstni agoniji je padla odločitev za temeljitejšo poglobitev v teorijo strukturnih funkcij v glasbi Wallaca Berryja ${ }^{1}$, a brez obremenjenosti z ambicijo "končno" najdene, "najboljše", "najprimernejše", "najpopolnejše" glasbeno-deskriptivne metode. Berryjevo razmišljanje me je pritegnilo s svojo težnjo, približati se boljšemu razumevanju glasbene strukture in izkušnje (doživljaja, ekspresivnega učinka glasbe) na način, v katerem sta domneva in intuicija (Berry pojmuje slednjo kot kreativno fuzijo pridobljenega znanja in izkušnje) bistveni v sprožanju vprašanj in odgovorov. ${ }^{2}$ Ali se vprašati: Kako glasba govori in kakšna je narava njenega jezika, se pravi premisliti in raziskati kontekstualni pomen (funkcijo) posameznih elementov strukture $v$ njihovem ekspresivnem učinkovanju. Tega naj ne bi, po njegovem, glasbena analiza nikakor obšla ${ }^{3}$.

Po Berryjevem mnenju je zmožnost povezanih glasbenih dogodkov (zaporedij, linij sprememb), da vzbujajo občutke napetosti (disonance, kompleksnosti, nestabilnosti itn.), sprostitve (razveza, sklepa) ter statičnosti, temeljnega pomena v glasbeni izkušnji, vsaj v tistem segmentu izkušnje, kjer sta mišljenje in čustvo (feeling) enakovredno soudeležena. In obratno: najpomembnejši aspekt glasbene izkušnje izvira iz medsebojnih delovanj (interactions) in odnosov (interrelations) med zaporednimi in hkratnimi dogodki različnih kakovosti znotraj kontekstualnih procesov, določenih s kontroliranimi linijami progresivnih in recesivnih sukcesij (17). Raziskovanje naj gre torej vzporedno z izkušnjo in naj bo njena razširitev: perceptibilno zaznaven vpliv in pomen enega dogodka v odnosu $\mathrm{z}$ ostalimi naj kot spodbuda privede do preiskave strukture, do njenih racionalno določljivih kvalitet, do funkcionalno-ekspresivnega pomena (26).

Izraz "funkcija" se pri Berryju nanaša na razvojno, procesualno vlogo nekega dogodka ali zaporedja dogodkov, oziroma na način njegove udeležbe v "uvozu" ekspresivne vsebine, ki je pri komponirani notirani glasbi jasen in racionalno razložljiv (22). Glasba je konstantno vpletena $\mathrm{v}$ dialektiko ( $\mathrm{v}$ sočasnih in zaporednih zvezah dogodkov), pri kateri sta nasprotni tendenci progresije in recesije ter njuni korelati, na primer zgorajspodaj, daleč-blizu, gosto-redko, enostavno-kompleksno, v nenehni medsebojni igri na različnih hierarhičnih ravneh (5). Koncept progresivnih in recesivnih aktivnosti znotraj "so-potekajočih" (confluent) elementov-struktur sugerira osnovni princip, da gre za "disonance" in "razveze" v okviru vseh glasbenih parametrov (elementov).

\footnotetext{
1 Wallace Berry, Structural functions in music, New York, 1987.

2 Berry se zaveda, da je nemogoče, da bi lahko kdaj dosegli popolno razumevanje posamezne glasbene izkušnje, tako kompleksni so namreč elementi glasbe, njihova delovanja in medsebojni učinki. Ib., 1.

3 Berry pravi: Reasoned premises concerning the functional-expressive connotations of events (and kinds of events) and concerning their interrelations and confluent parallel or resistant tendencies and interactions are indispensable in analysis. Ib., 10.
} 
Vsi elementi-strukture $v$ danih primerih sočasnih linij sprememb nimajo enakega pomena ali pa ga sploh nimajo (5), zato je pri analizi medsebojno učinkujočih in hierarhično urejenih "delovanj" (element-actions) potrebno najprej določiti, kje se prispevajoči dogodki pojavijo. Ti se po stopnji in vrsti (ne)aktivnosti v "napetostni" tendenci (progresije, recesije, statičnosti) določenega dela skladbe lahko dopolnjujejo (so komplementarni, complementary, parallel) ali si nasprotujejo (so nasprotno delujoči, kompenzacijski, counteractive, compensatory). Pri tem je pomembno upoštevati idejo hierarhično urejenih ravni, ki se nanašajo na obseg konteksta, obseg opazovanega predmeta (takta, večje metrične enote, fraze, odseka, dela, polovice skladbe ipd.), kajti lahko se pojavi statičnost znotraj nekega strukturnega elementa na širši ravni, na najnižji pa se dogaja aktivnost (13-15).

Berryjeva raziskava se v veliki meri osredotoča na teorije ritma in teksture ${ }^{4}$ ki jima je, kot pravi, v obstoječi glasbeno-teoretični literaturi posvečeno le malo pozornosti, sta pa po njegovem mnenju dva vitalna faktorja $v$ glasbeni strukturi in izkušnji, zato so tonalni, harmonski in melodični sistemi $v$ njegovi knjigi raziskani le kot vzporedni ter součinkujoči (1-2). Namen pričujočega sestavka ni predstaviti Berryjevih teorij, njihovih dokazovanj in dvomov do potankosti, še manj jih kritično ovrednotiti, pač pa s pomočjo njegovih pojmovanj in formulacij razširiti analitični pojmovno-besedni inštrumentarij opazovanih vrednosti strukturnega elementa-teksture in njegovih parametrov.

$\mathrm{K}$ osredotočenju na teksturo me je privabila trditev, da so spremembe v tovrstni strukturi pogosto med najlažje perceptibilnimi in dojemljivimi v glasbeni izkušnji (189). Prepoznavanje in ovrednotenje njenih kvalitet sta po Berryju pomembni za razumevanje sloga in slogovnih obdobij (200), tekstura pa je tudi bistven element, s katerim postane razločna in ekspresivna tematska vsebina določene skladbe (236). Zato so teksturni dogodki na vseh ravneh strukture neprecenljivega pomena $\mathrm{v}$ orisu in procesualnem oblikovanju vseh oblikovnih prototipov in vseh oblik pred ter po tonalni periodi (240). Poleg tega je Berryjevo videnje teksture tako široko in kompleksno, da se dotika ali celo posega v območja domala vseh strukturnih elementov. Naj bodo najprej na kratko predstavljene nekatere njegove temeljne premise in definicije o tem, $v$ drugem delu pa poskus teksturne analize na primeru Žebretove skladbe.

\section{O teksturi po Berryju}

Teksturo definira Berry kot element glasbene strukture, ki je določen z glasom oz. številom glasov ter ostalih komponent, ki prenašajo glasbeno gradivo v zvočni medij, in z odnosi oziroma učinkovanji med njimi (191). Ker je sestavljena iz zvenečih komponent, je pogojena deloma s številom, obsegom, razvrstitvijo teh komponent (kvantitativni aspekt), deloma pa $z$ medučinkovanji med njimi (kvalitativni aspekt). Kvantitavni aspekt teksture pripisuje Berry teksturni gostoti (density), pri kateri ločuje teksturni obseg (density-space), gostotno število (density-number) in gostotno stisnjenost (density-compression). Teksturni obseg definira kot zaprto polje, začrtano $z$ linijami zaporedij tonskih višin zunanjih komponent (249). Gostotno število je število vseh zvenečih komponent (glasov) $)^{5}$, gostotna stisnjenost pa razmerje tega števila do danega celotnega prostora

\footnotetext{
${ }^{4}$ Eno poglavje v knjigi je posvečeno tudi tonalnosti (str. 27-183).

5 Berry ločuje "zveneče" (sounding) komponente od "dejanskih" faktorjev (real factor). Npr. dve liniji, ki se gibljeta v vzporednih tercah, tvorita en sam teksturni faktor, sestavljen iz dveh komponent. Na mestu, kjer se zgodi sprememba - v ritmu, smeri ali razdalji gibanja ipd., iz dveh zvenečih komponent in enega dejanskega faktorja nastaneta dva dejanska faktorja. The term 'component' may refer generically to any textural ingredient or factor as indicated in the immediate context of consideration, and as qualified by such adjectival modifiers as 'real' component, 'inactive' component, 'doubling' component, etc. Ib., 186.
} 
(razmaka, obsega, space) ${ }^{6}$. Gostotna stisnjenost je bistveno povezana z disonanco, nadaljni aspekt teksture pa je tudi zvočna barva (npr. vertikalno zaporedje dogodkov je lahko instrumentacijsko zasnovano "zlito" ali "ločeno").

Kvalitativno teksturno vrednost določajo razmerja med zvočnimi komponentami in njihova medsebojna učinkovanja, pri čemer je v ospredju kriterij njihove relativne neodvisnosti oziroma soodvisnosti (skladnosti, ujemanja, kongruence). Bistveni faktorji za slednjo so smerna, intervalna in ritmična soglasnost oziroma različnost ter odnosi motivičnega gradiva (vključujoč imitacijo). Gibanje hkratnih melodičnih zaporedij je lahko istosmerno, raznosmerno, nasprotnosmerno; homoritmično, heteroritmično, nasprotnoritmično; in istointervalno, raznointervalno ter nasprotnointervalno (193). Spekter teksturnih pogojev ali vrednosti od enostavne (monofonske) do kompleksne (večglasne, nasprotnoritmične, nasprotnointervalne, nasprotnosmerne, kar je najvišja manifestacija polifonije) teksture je širok, služi kot leksikalna osnova za analizo (193). Berry nato opiše deset tipov teksture, ter razgrne nadaljne probleme o klasifikaciji in terminologiji (192). Imitacija je po njegovem najvišja manifestacija medlinijske samostojnosti ${ }^{7}$ in je najbolj prepričljivo nasprotje medlinijske skladnosti, "ideala" mirovanja, proti kateremu teksturni procesi končno težijo.

\section{Tekstura v skladbi Svobodi naproti D. Žebreta}

Simfonična pesnitev Svobodi naproti, ki jo je Žebre ustvaril leta 1944, bo služila tukaj le kot model za poskus "praktične" aplikacije Berryjevega predloga o teksturni analizi in ne bo predmet celovitejše obravnave. V okviru analize teksture bo v pričujočem besedilu namerno opuščeno opazovanje gostotne stisnjenosti, ker je ta teksturni parameter močno povezan $z$ disonanco, slednja pa neizbežno $z$ intervalnimi razmerji med vertikalno razvrščenimi toni, torej s teorijo harmonije 20. stoletja. Zanemarjena bo instrumentacija kot del zvočnega barvanja, čeprav za funkcijo teksture ni nepomemben faktor. Prav tako zahteva podrobnejšo in ločeno obravnavo. Nasprotno pa bosta od ostalih strukturnih elementov upoštevani kot najlaže slušno prepoznavni (in v partituri "vidni") stopnja dinamične jakosti ${ }^{8}$ in tonska višina, katerih linije sprememb so mi bile $\mathrm{v}$ veliko pomoč pri začrtanju napetostne krivulje (intensity curve) 9

\section{Analiza napetostne krivulje ${ }^{10}$}

Procesi sproščanja in naraščanja napetosti so $\mathrm{v}$ skladbi $\mathrm{v}$ pogostem menjavanju, so njeno "dihanje": izmenjujejo se v okviru posameznih fraz, odsekov, kot tudi večjih de-

\footnotetext{
${ }^{6}$ Vprašanje gostote, zlasti gostotne stisnjenosti, je zelo kompleksno, pravi Berry. Gostotna stisnjenost npr. 3: 24 še ne pove vsega - pomeni le to, da so v razmaku treh oktav razvrščeni trije toni. Zunanja dva sta znana, ker zamejujeta obseg. Bistvena je porazdelitev notranjega oz. notranjih glasov. Moramo razlikovati med relativno večjo tendenco po "zlitju" med komponentami (intervali $4,5,8$ ) nasproti bolj heterogenim disonantnim intervalnim vsebinam. To zadeva povezanost gostote z disonanco, ki mora biti upoštevana kot pogojujoč faktor. Ib., 209.

7 Krajši ko je časovni interval, meni Berry, bolj napet konflikt nastane iz kontradikcije motivične sorodnosti in časovne ločenosti. Krajšanje razdalje $\mathrm{v}$ imitaciji je osnova za stretto, spreminjanje tega nasploh pa je funkcionalno $\mathrm{v}$ mnogih glasbenih kontekstih in slogih. Ib., 216-217.

${ }^{8}$ O pomembnem vplivu dinamičnih stopenj na glasbeno izkušnjo pravi Berry naslednje: / .../ it seems well to make a point of the fact that one vital aspect of coloration, that expressed in dynamic levels, often goes very far indeed in accounting for the nature of musical experience and meaning. Ib., 20.

9 Zgleda za takšno krivuljo, ki bi nakazala nihanja napetosti v splošnem in v celotni skladbi, ne daje Berry nikjer, zato je nastala po zamisli avtorice tega članka.

${ }^{10}$ Grafični prikaz krivulje je le poskus poenostavljenega in zato približnega zapisa nihanja napetosti glasbenega toka $\mathrm{v}$ skladbi, nastalega na temelju slušne izkušnje in notnega zapisa. Kazala naj bi potek progresivno-recesivnih procesov v skladbi, ki rezultirajo v součinkovanju vseh elementov-struktur in služijo za izhodišče obravnave funkcionalnega prispevka vsakega od njih, v tem primeru teksture.
} 
lov, polovice, celote. Mesta statičnosti so krajša in v manjšini. Najbolj statično učinkujejo ponovitve A in B teme (A', A", A"', B'), torej znane, vračajoče se "potrditve", najbolj napetostno razgibano, $\mathrm{v}$ smislu progresivno-recesivnih valovanj pa prve predstavitve vseh treh tem (A, B, C), prizorišča "novega dogajanja". Te se pojavijo v daljših kompleksih z nekaj ponovitvami. Nekaj progresivno-recesivnega nihanja je tudi v medigrah, za katere je značilno stopnjevanje napetosti (ponavadi v dveh progresivno-recesivnih lokih) pred bodisi novim tematskim območjem ali ponovljeno temo. Vse to skladbo "muzikantsko" razgiba oziroma ji daje "pripovedno" živost. Iz grafičnega prikaza krivulje je tudi razvidno, da del A učinkuje recesivno, medtem ko sta tematska kompleksa B in C progresivno napetostno naravnana.

Ker način razporeditve treh večjih tematskih kompleksov (A, B, C) skladbo razpolovi približno na sredini (takt 97 od 207), sta polovici njena najvišja hierarhična raven pred celoto. Prva polovica skladbe (A-M1-B-M2-A') bolj napetostno niha: začne se $\mathrm{z}$ daljšo recesijo (1-34), sledijo pa ji tri srednje dolge progresije $z$ vmesnimi, zelo kratkimi recesijami, ki jih s širše perspektive lahko zanemarimo, tako da dobimo recesivno-progresivno tendenco.Ta je sicer značilna tudi za drugi del (Uvod-C-M3-A"-B'-M4-A"'), vendar z razliko, da je recesija tu zelo kratka, a je zaradi močnega učinka ne moremo zanemariti (pettaktni Uvod), progresija, ki ji sledi, pa kaže veliko večjo zveznost v poteku, brez dodatnih nihanj navzdol in se nádaljuje do konca skladbe. Na najvišji ravni - ravni celote je ekspresivnost glasbe recesivno-progresivna, $s$ tem, da je progresija približno sedemkrat daljša od začetne recesije. To je bil zelo pomemben faktor pri prepoznavanju oblike (med drugim tudi njene dvoumnosti), ki je lahko predmet posebne razprave, in je v tem spisu zaobideno. Za lažje poimenovanje posameznih delov in glede na razporeditev ter skladateljevo obravnavo motivično-tematskega gradiva, ki kaže rondojsko zasnovo skladbe, se je zdel logičen pričujoč prerez skladbe:

\section{Primer 1: Grafični prikaz napetostne krivulje in njenih poenostavitev}

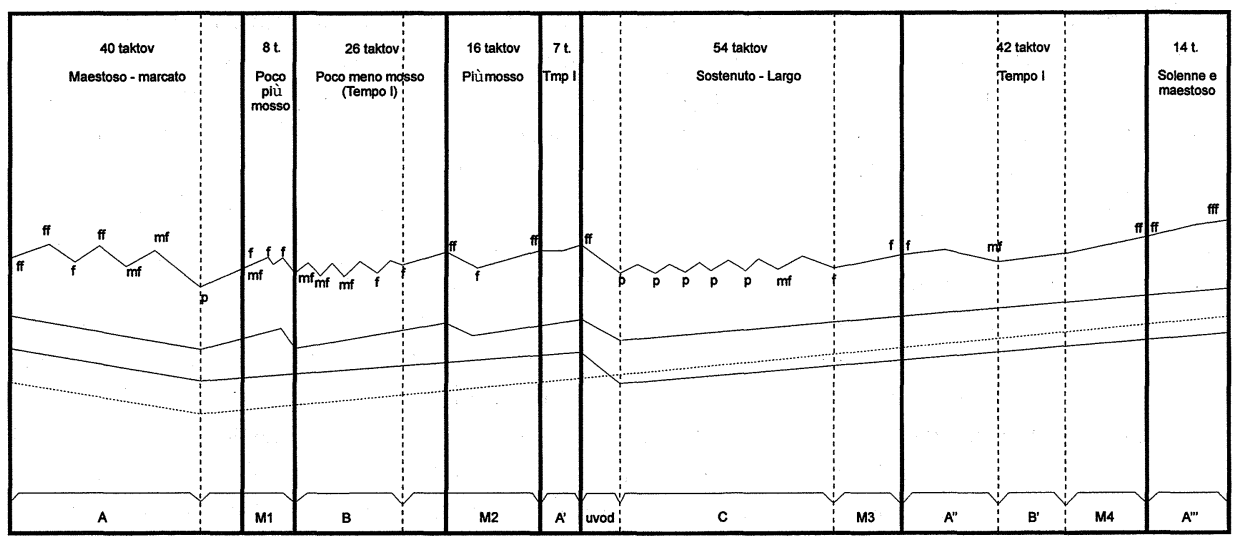

\section{Tekstura}

Tekstura je bistven element, s katerim postane tematska vsebina skladbe Svobodi naproti razločna in ekspresivna. Kontrasti med temami, njihovimi zaporednimi ponovitvami oziroma tematskimi območji ter medigrami, so večidel teksturni, s teksturnimi razlikami, ki igrajo analogno ali kompenzacijsko vlogo s spremembami tonalnih zvez, tonske višine v horizontali, harmonskih zaporedij, dinamičnih stopenj in podobno. Tekstur- 
ni dogodki, kontrasti in variacije sodijo $\mathrm{k}$ temeljni tehniki pri delu $\mathrm{z}$ motivičnim gradivom, $v$ tematsko izrazitih in manj izrazitih delih skladbe ter na vseh hierarhičnih ravneh: na ravni motiva, fraze, odseka, dela, skladbe. Razpon teksturnih pogojev je širok: od maksimalne teksturne kompleksnosti do medlinijskega skladja, od zasedenosti celotnega orkestra (maksimalnega gostotnega števila) do monofonije. Poleg tega je tekstura tesno povezana s zvočnostjo skladbe. Le to preddoloča s podvajanjem glasov in barvanjem, katerega del je poleg artikulacije ter zvočne jakosti tudi instrumentacija.

\section{Tekstura na ravni posameznih delov skladbe in na ravni njihovih odsekov}

\section{Teme in tematski kompleksi $(A, B, C)$}

Pri načinu Žebretovega strukturiranja posameznih tematskih kompleksov najdemo več podobnosti. Ena je ta, da so vse teme po prvi predstavitvi nekajkrat ponovljene (melodično dosledno ali variirano): A se dvakrat ponovi, B trikrat, $C$ pa petkrat. Njihovi vsakokratni nastopi so oblikovani $\mathrm{v}$ progresivno-recesivni lok tonske višine (vsaka tema ima obliko navzdol obrnjene krivulje dvigajoče-padajočih zaporedij tonov) s komplementarno funkcijo zvočne jakosti na več mestih (gl. crescendo pred nastopom najvišjih tonov, decrescendo pri padajočih melodičnih linijah). Edini izjemi sta tretji in četrti nastop druge teme, kjer so tonska zaporedja pretežno vpenjajoča. Tematski kompleksi kot celote pa se v napetostni tendenci razlikujejo: A-del deluje recesivno, ostala dva pa progresivno.

Najprej se zastavlja vprašanje, kakšno strukturno funkcijo ima tekstura v tako oblikovanem napetostnem nihanju posameznih nastopov tem in kakšno v ekspresivnem učinku posameznih tematskih kompleksov (sklopov).

Ker se v B-delu tekstura na ravni posameznih nastopov teme ne spreminja, si velja pobliže ogledati teksturne spremembe v okviru posameznih fraz v A ter C-delu.

V A-delu (1-33), ki je sestavljen iz treh odsekov (fraz), treh zaporednih nastopov glavne teme (prva polovica teme se pojavi še kot kontrapunkt $\mathrm{k}$ drugi polovici istega nastopa pri prvem nastopu, je teksturni ritem pri vsakem nastopu teme linijam tonske višine in dinamične stopnje komplementaren: teksturna sprememba nastopi na višku z najvišjim tonom in obratom smeri melodičnega gibanja navzdol, približno na polovici vsakega nastopa teme. V okviru posamezne fraze je tako tekstura recesivna (prva polovica : drugi polovici) v gostotnem številu, teksturni kompleksnosti, zvočni barvitosti (gl. podvajanja) in $\mathrm{v}$ teksturnem obsegu. Teksturni obseg je najpogosteje spreminjajoča se komponenta teksture, saj se (lahko) spremeni pri vsakem tonu (akordu) v horizonatali. Ker je na splošno $v$ veliki meri pogojen $s$ smerjo melodične linije, kaže tudi progresivno-recesivno tendenco (največji je tam, kjer doseže melodična linija najvišji ton). Glej 2. primer.

V prvi polovici prve fraze (1-6) je orkester polno zaseden ${ }^{11}$. Visoko razmerje vseh zvenečih glasov do dejanskih faktorjev teksture ("realnozvenečih" oziroma različnih linij, brez podvojitev) kaže maksimalno gostotno število, povečano barvitost in bogatost zvoka (eden od faktorjev je tudi harmonija). Ta del prvega teminega nastopa je sestavljen iz štirih subtekstur: treh enoglasnih in ene troglasne, slednja je iz akordsko soodvisnih tonov $s$ funkcijo harmonskega barvanja. Enoglasne (všteta je basova) so med seboj raznosmerne, heteroritmične in raznointervalne ${ }^{12}$. Tekstura in gostotno število se nenadno zelo spreme-

\footnotetext{
${ }^{11} \mathrm{Ob}$ številnih podvojitvah $\mathrm{v}$ oktavi in unisonu ter $\mathrm{z}$ dodatnimi oktavnimi podvojitvami znotraj prvih violin in fagotov (tu le $\mathrm{v}$ prvih dveh taktih).

${ }^{12}$ Edino v t. 3-4 je basova linija nasprotnosmerna glavni melodiji (to je mesto enega od dvigov tonske višine pred viškom in povečanega teksturnega obsega).
} 
Primer 2: Prva tema, začetek

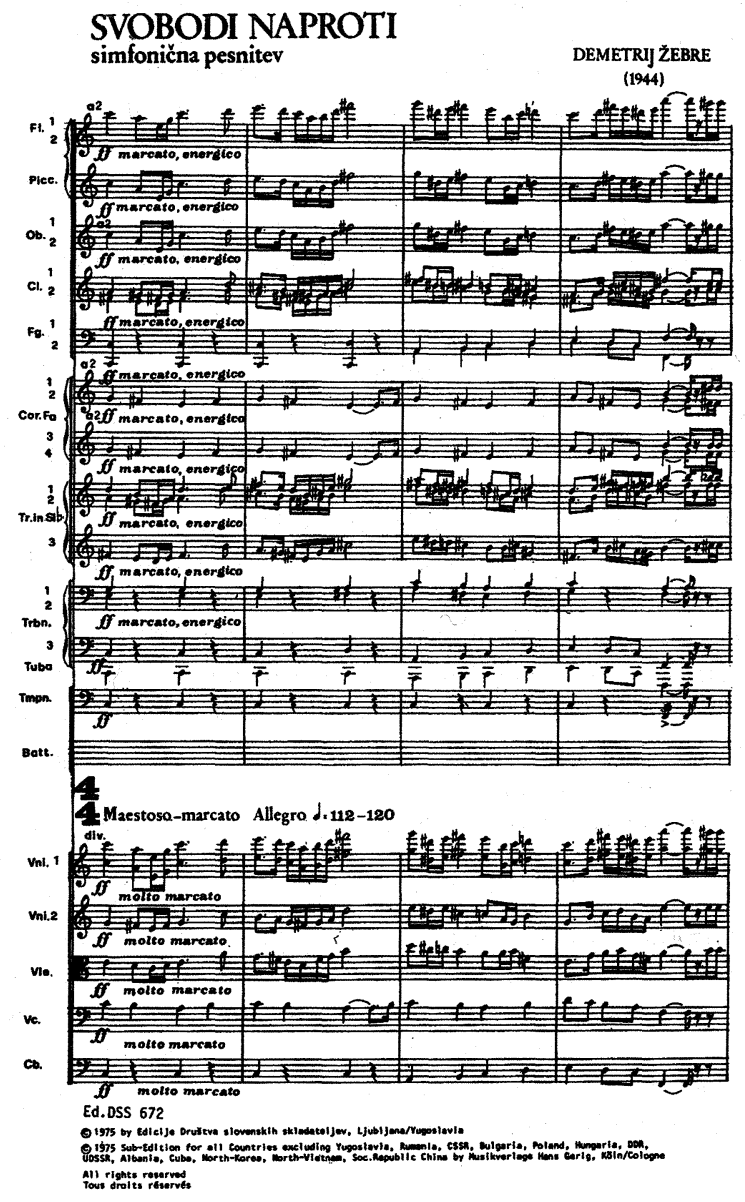

nita (padec s 23 na 6) v taktu obrata (6), a le za en takt, dokler se progresivna tendenca glasbe ne spremeni $v$ recesivno, ko nastopi $\mathrm{z}$ najvišjim tonom sproščanje vseh komplementarno (so)delujočih strukturnih elementov. Tekstura $v$ drugi polovici fraze (7-12) kaže poleg manjšega gostotnega števila ${ }^{13}$ in teksturnega obsega tudi večjo transparentnost, ki je posledica padca gostotnega števila ter razmerja med vsemi zvenečimi in "realnozvenečimi" komponentami. ${ }^{14}$ Kompleksnost teksture je tako med polovicama celotne fraze komplementarno recesivna v efektu, saj od štirih teksturnih slojev ostanejo trije, ki so sicer med seboj tudi neodvisni, so pa veliko manj podvojeni. Kvalitativni aspekt teksture je v primerjavi s kvantitativnim (gostotno število, gostotna stisnjenost, teksturni obseg) kljub temu manj spremenjen, četudi je komplementaren splošni recesivni tendenci.

\footnotetext{
${ }^{13} 10,11,14$ - gre zgolj za teksturno variacijo na najnižji hierarhični ravni.

${ }^{14}$ Realno zvenijo trije glasovi, sodelujočih je pa 10 , medtem ko je bilo to razmerje v prvem delu $6: 23$.
} 
Pri drugem nastopu teme (13-20) ima tekstura enako funkcijo v progresivno-recesivnem dvigovanju in padanju tonske višine ter dinamičnih stopenj kot pri prvi frazi in $\mathrm{z}$ istimi teksturnimi prijemi (tehnikami) ${ }^{15}$, saj se spremeni $v$ gostotnem številu ${ }^{16}, \mathrm{v}$ teksturnem obsegu ${ }^{17}$ in $v$ teksturni kompleksnosti ${ }^{18}$. Z zmanjšanjem števila teksturnih komponent in plasti je posledično zmanjšana (kvantiteta vpliva na kvaliteto) tudi stopnja medlinijske neodvisnosti, ki pa je manjša predvsem zato, ker sta (ohranjena) enoglasna glavna melodična komponenta in kompleks triglasnih soodvisnih glasov v medsebojnem razmerju manj nasprotnoaktivna oziroma manj neodvisna.

Tretji nastop teme (21-33) kaže manjše odstopanje od prvih dveh: začne se s štirimi teksturnimi plastmi (s tremi enoglasnimi in dvoglasno figuralno), torej s petimi dejanskimi komponentami, ki se $\mathrm{v}$ drugem delu povečajo na šest ${ }^{19}$. Tudi gostotno število je $\mathrm{v}$ drugem delu progresivno (z 9 na 10). Številčno enaka ostane medlinijska neodvisnost glasov, vendar ne njen učinek: glavna melodija ostane edina tematsko izrazita linija (prej sta bili dve), saj so ostale tri zasnovane ostinatno, v smislu sekventno ponovljenega dvotaktnega vzorca in zato $\mathrm{v}$ ekspresivnem učinku statične ${ }^{20}$. Zaznavna je torej tendenca $\mathrm{k}$ večjemu linijskemu skladju, barvitosti in polnosti zvoka ob koncu tematskega dela, oziroma kompenzacijska funkcija teksture v splošni napetostni tendenci. Ta Žebretova teksturna tehnika je konstanta, ki se pogosto pojavlja kot sredstvo zaključevanja in kot priprava temu sledečega teksturnega kontrasta. Recesivnost teksture na ravni cele fraze je tako prisotna le $\mathrm{v}$ zmanjšanju tematsko izrazitih komponent $\mathrm{z}$ dve na eno in $\mathrm{v}$ teksturnem obsegu ${ }^{21}$. Omeniti je treba tudi mesti nenadne in kratkotrajne kvantitativne in kvalitativne teksturne recesije (dolgi po 1 takt): mesto hitrega melodičnega vzpona $\mathrm{k}$ drugemu melodičnemu višku (28) in zadnji takt v frazi (33). ${ }^{22}$

Če je teksturna sprememba $v$ A-delu na sredini posamezne fraze vedno drugačna in pretežno komplementarna napetostni tendenci, je pri posameznih nastopih C-teme (prim. 4) na ravni fraze sicer nespremenjena $v$ večini teksturnih plasti, vendar jo, če zanemarimo občasne dodane kratke motive, $\mathrm{v}$ drugem delu vsakič obogati dodaten melodično neodvisen glas (kontrapunkt). To prispeva $\mathrm{k}$ njeni kompleksnosti in povečanemu gostotnemu številu, zato je progresivno-recesivnemu poteku tonske višine in jakosti nasprotnodelujoča (kompenzacijska). Pri tretjem in četrtem nastopu (gre za transpozicijo) je izjemoma v vsaki polovici drugačna: gostotno število konstantno udeleženih glasov v prvih polovicah bistveno zaniha navzdol (gl. prim. 3).

\footnotetext{
${ }^{15}$ Omeniti velja skrajšanje drugega dela te fraze, tako da je progresija dolga 5 taktov, recesija pa 3 (v prvi frazi 6:5). Motivično variiran je le ta del (prvi je dosledno ponovljen).

${ }^{16} \mathrm{~S} 13$ na 10 in 6 glasov, torej postopno.

${ }^{17}$ Ta se zmanjša s 40 (na začetku fraze) oziroma 47 poltonov (na sredini) na 12 poltonov, oziroma meri A-c3 na začetku fraze, c-b3 na progresivnem višku, cis-cis1 na koncu fraze.

${ }^{18} \mathrm{~V}$ prvem delu (13-17) je sestavljena iz petih teksturnih plasti: treh enoglasnih, ene triglasne in ene ritmične. Enoglasno zvenijo (kljub podvojitvam $\mathrm{v}$ unisonu ali oktavi) linija teme, njen kontrapunkt in basovska linija. V medsebojnem odnosu so raznosmerne, heteroritmične in raznointervalne. Triglasni kompleks akordsko skladnih tonov je čez celotno frazo izoritmičen, y obliki enakomernega pulsiranja na vsako dobo (staccato), in ritmično identičen z udarci na boben. $\mathrm{V}$ drugem delu (18-20) pa se število udeleženih teksturnih komponent najprej zmanjša na štiri (t. 18), v zadnjih dveh taktih pa na tri.

${ }^{19}$ Tam število teksturnih plasti ostaja isto, le da še ena od teh postane dvoglasna, terčno podvojena.

${ }^{20}$ Podobno učinkujeta $\mathrm{v}$ prvem delu te fraze gibanje basovske linije in figuralna terčna plast.

${ }^{21}$ FIS-a2 na začetku fraze, GIS-h2 na prvem melodičnem višku, c-h2 na drugem melodičnem višku, c-e1 na koncu fraze in a-c1 v zadnjem taktu.

${ }^{22} \mathrm{~V}$ t. 28 je tekstura razredčena na tri, v drugi polovici takta celo na dve plasti, $\mathrm{v}$ zadnjem taktu pa na en sam glas.
} 
Primer 3:*

\begin{tabular}{|c|c|c|c|c|c|}
\hline 1. nastop teme & 2. nastop & 3. nastop & 4. nastop & 5. nastop & 6. nastop \\
\hline & & II. & II. & & \\
\hline $5(10)$ & $7(9)$ & $4(7) 8$ & $4(7) 8$ & $11(15)$ & $10(14)$ \\
\hline
\end{tabular}

To sta mesti večje teksturne redkosti in enostavnosti na ravni tega tematskega kompleksa $^{23}$, vendar $\mathrm{z}$ določenim namenom, kar je lep primer učinkovite rabe teksturne strukture pri Žebretu. Teksturni kontrast, melodična variacija (nastopa sta melodično variirana) in dinamična recesija ( $\mathrm{p}$-pp - ta je nasprotna tendenci drugih nastopov teme) ustvarjajo občutek napetosti, pričakovanja pred vpeljavo dodatne (v motivičnem gradivu že znane) teme, izpeljane iz Uvoda. Ta nastopi $\mathrm{v}$ tritaktnem prehodu med četrtim in petim nastopom, v katerem se teksturni obseg strahovito in nenadno skrči (A-As3 > c-e1 < As-c3).

Primer 4: Tretja tema, začetek

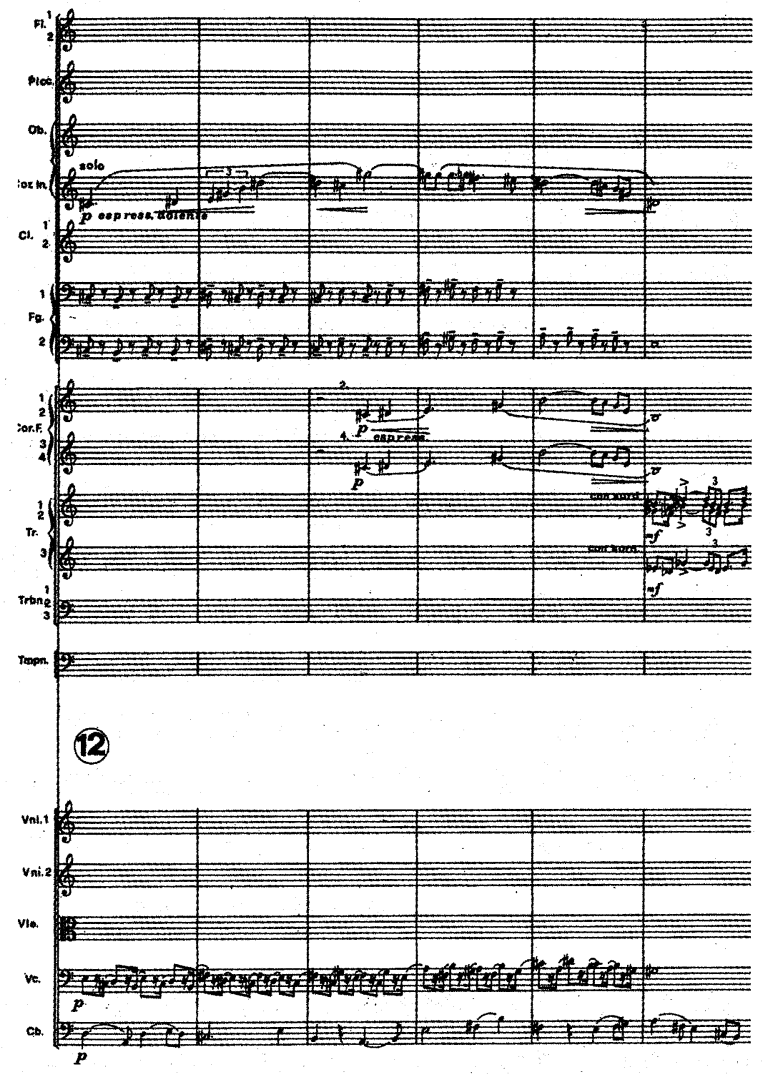

* Prva številka pove, koliko je konstantno udeleženih glasov, številka v oklepaju pa število vseh, tudi občasno oziroma za kratek čas pridruženih glasov.

${ }^{23}$ Sodelujeta dve realni komponenti: glavna melodija in spremljevalni ostinatni figuralni glas, podvojen $v$ kvartah. Po treh dobah se jima pridruži akordski triglasni motiv. V drugi polovici se glavni melodični liniji pridruži še ena v kontrapunktskem odnosu, dodani sta še v oktavah podvojena komponenta figur in triglasna ležeča akordska plast. 
Če sedaj pogledamo funkcijo teksture na ravni posameznih tematskih kompleksov $\mathrm{v}$ njihovi napetostni tendenci, ugotovimo komplementarnost teksturne spremembe $\mathrm{v}$ posameznih od njih vse do zadnjega nastopa tem - recesivnost večine teksturnih parametrov v A-delu, in progresivnost $\mathrm{v}$ B ter C-delu. Vendar je pozornosti vredna prav kompenzacijska (nasprotnoaktivna) tekstura ob njihovih sklepih, že omenjena Žebretova tehnika. Lep primer za to ponuja drugo tematsko območje.

$\mathrm{Z}$ območjem druge teme (B, 49-64) se glasbeni tok vrne v izhodiščni tempo (Poco meno mosso (Tempo I)). Po predhodni gradaciji v medigri tako poleg recesivnega dogodka $\mathrm{v}$ hitrosti nastopi tudi recesivna sprememba $\mathrm{v}$ teksturi oziroma teksturni kontrast, ki je najbolj očiten $v$ zmanjšanju vseh zvenečih glasov (gostotnem številu), posledično $s$ tem $\mathrm{v}$ podvajanju in $\mathrm{v}$ teksturnem obsegu.

Štirje nastopi druge teme razdelijo ta del na štiri odseke, dolge po štiri takte, kolikor jih šteje tema (prim. 5), ki je variirana predvsem s transpozicijo v druga tonalitetna območja, vsakič za terco više (A-C-E-G). Motivična vsebina teme ostaja pri posameznih ponovitvah popolnoma enaka, zato pride tukaj toliko bolj do izraza teksturna variacija.

Primer 5: Druga tema, začetek

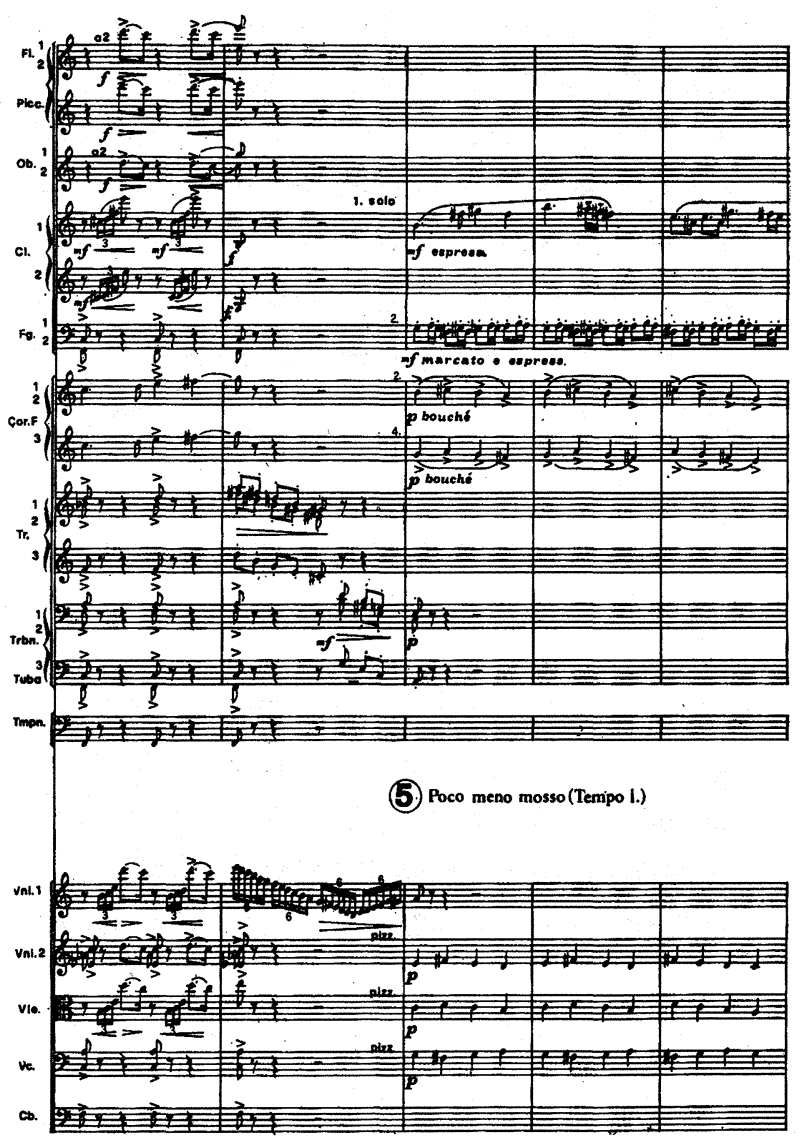


$\mathrm{V}$ splošni progresivni tendenci med posameznimi nastopi teme (dvigovanje tonske višine za terco, dinamika $\mathrm{mf}-\mathrm{mf}-\mathrm{mf}-\mathrm{f}$ ) učinkuje tekstura kot celota komplementarno le do tretjega nastopa teme. Nenehno se povečujeta teksturni obseg (d-a2; G-c3; F-e3; G'-g3) in podvajanje, ostali teksturni parametri pa delujejo v zadnjem četrttaktju recesivno: gostotno število $(7,9,13,10)$, število dejanskih komponent $(5,6,8,2)$, število teksturnih plasti $(3,4$, $6,2)$, medlinijska neodvisnost (na koncu ji sledi medlinijska skladnost) in kompleksnost teksture, ki se pri četrtem nastopu teme zreducira na dve, sicer močno podvojeni enoglasni realni komponenti (prim. 6). Torej je tekstura $\mathrm{z}$ večino svojih parametrov v B-delu progresivno-recesivna, višek medlinijske neodvisnosti je pri tretjem nastopu teme.

\section{Primer 6:*}

\begin{tabular}{|c|c|c|c|}
\hline$(49-52)$ & $(53-56)$ & $(57-60)$ & (61-64) \\
\hline $\begin{array}{l}\text { 1. nastop } \\
\text { teme }\end{array}$ & 2. nastop & 3. nastop & 4. nastop \\
\hline 1 & 2 (1-gl.) & 2 (1-gl.) & 7 (1-gl.) \\
\hline 1 & 2 (1-gl.) & 2 (1-gl.) & 3 (1-gl.) \\
\hline 5 (3-gl.) & 4 (3-gl.) & 3 (3-gl.) & \\
\hline & 1 & 3 (1-gl.) & $10(2)$ \\
\hline \multirow[t]{3}{*}{$7(5)$} & & & \\
\hline & $9(5)$ & 2 (1-gl.) & \\
\hline & & $13(\varepsilon$ & \\
\hline
\end{tabular}

Ponovitve A in B teme (A', A", A', B')

Prva polovica prvega nastopa A-teme, prvo njeno "vrnitev" za drugim tematskim območjem in dvema medigrama (A') ter njen zadnji nastop (konec skladbe $-\mathbf{A}$ "') je Žebre podčrtal $\mathrm{z}$ enako teksturno kvaliteto: $\mathrm{z}$ zvenenjem vseh orkestrskih glasov in $\mathrm{s}$ sestavljeno (kompleksno) teksturo, v kateri prevladuje medlinijska skladnost spremljevalnih glasov (podvojitve). Tako je izpostavil temo, z barvito zvočnostjo pa podčrtal pomembnost teh odsekov. Zlasti mogočno zveni sklepna "potrditev" teme, pomemben strukturni faktor takšnega učinka pa je tudi njena ritmična avgmentancija.

Drugačno vlogo pa je dodelil drugi ponovitvi A-teme (A", 151-158) ter prvi (in edini) ponovitvi B-teme (B', 159-166). Umeščeni sta med tretjo in četrto medigro ter postaneta tako del dolge progresije v drugi polovici skladbe, ki "spominja" na izpeljavo, saj njuna ponovitev ni dovolj "prepričljiva". To je dosegel Žebre prav s teksturo. Najprej je vrnitev prve teme (151-156) podčrtal s teksturnim kontrastom glede na predhodni del in predhodno progresijo, zato deluje ta recesivno, sproščujoče. Tekstura je zelo razredčena: na eno realno melodično komponento in ostinatno subteksturo iz dveh izoritmičnih, heterofonskih komponent, ki se jima na koncu fraze pridruži še petglasna akordska plast. Prehod k B'-odseku deluje napetostno "pripravljalno", z že na več mestih uporabljeno Žebretovo tehniko padajočega lestvičnega zaporedja tonov ob povečani zvočni jakosti in artikulaciji ter z minimalno teksturno gostoto. B', kjer sta kontrapunktično soočeni A in B-tema, je teksturno gostejši, večplasten in $z$ visoko stopnjo medlinijske neodvisnosti. ${ }^{24}$ Ekspresivni učinek A" in B'-dela je tako dvoumen: niha med repriznim in izpeljevalnim.

\footnotetext{
* Številka pod črto na levi pove število vseh udeleženih glasov v teksturi, številka v oklepaju pa število "realnozvenečih" glasov brez podvojitev. Vsaka posamezna plast teksture je v svoji vrstici.

${ }^{24} \mathrm{Nad}$ enkrat avgmentirano prvo temo se dvakrat ponovi druga tema (B'), temu pa sta dodani še dve kontrapunktski liniji ter akordska plast.
} 


\section{Medigre}

Medigre so najbolj teksturno razgibana mesta $\mathrm{v}$ skladbi, saj je menjava teksture $\mathrm{v}$ njih hitrejša kot kjerkoli drugje (celo na takt), glasbeni tok pa je razdrobljen na motive in njihovo izpeljevanje (motivično-tematsko delo). Večinoma so sestavljene iz dveh ali treh, med seboj kontrastnih odsekov. Vse so progresivno naravnane, $v$ enem ali dveh napetostnih lokih, $s$ kakšnim vmesnim viškom. V vseh se napetost stopnjuje pred sledečim tematskim območjem (novim, bodisi ponovljenim), ki učinkuje enkrat kot sprostitev (ko M1 sledi B), drugič kot statični podaljšek viška oziroma sam višek (gl. M2-A', M3-A', M4-A"'). Žebre pogosto $\mathrm{v}$ medigrah uporabi strettne tehnike naraščanja napetosti, $\mathrm{v}$ katerih je pomembno udeležena tudi tekstura.

Za primer vzemimo drugi odsek prve medigre (M1, 41-49), ki poteka v "bolj razgibanem" tempu (Poco più mosso) in gradacijo pripelje do cilja zlasti s tehnikami metričnega krčenja in pospeševanja teksturnega ritma. Sestoji iz dveh, sekvenčno ponovljenih štiritaktij ${ }^{25}$. Tekstura je triplastna: iz dveh melodično samostojnih dejanskih komponent in ene petglasne akordske. Prvo komponento neprekinjeno čez vsako štiritaktje izvajajo prve violine in viole v oktavni podvojitvi, s prekinitvijo in izmenjaje na pol takta oziroma na njegovo četrtino pa si jo podajajo klarinet in flavta skupaj z oboo (podvajanja, $v$ unisonu ali oktavi). Drugo melodično komponento izvajajo rogovi v unisonu, akordska pa se pojavi dvakrat le kot za osminko trajajoče barvanje: dvakrat na prvo dobo takta, tretjič pa na prvo in tretjo dobo $v$ vsakem četrttaktju. Pospešen teksturni ritem $v$ okviru vsakega četrttaktja (menjava teksture na $1 / 2,1 / 2,1 / 4 ; 1 / 2,1 / 2,1 / 4$ takta) je usklajen $\mathrm{z}$ metrično strukturo oz. pospeševanjem $1,1,2 ; 1,1,2$ poudarka na takt), $\mathrm{z}$ motivičnim deljenjem in $\mathrm{z}$ ritmom harmonskega barvanja.

Žebre uporabi tu spet polno zaseden orkester, vendar nikoli istočasno, zato je deljenje na različne zvočnobarvno učinkujoče instrumente (skupine) in njihovo izmenjavanje dodatna teksturna posebnost tega odseka.

Omeniti velja še prvi odsek druge medigre (M2, 65-77). Tekstura je v prvih dveh trotaktjih tudi sekvenčno ponovljena (kot vsi drugi strukturni elementi). Prvič v skladbi postane akordska plast "melodično" vodilna, v variirani obliki se ponovi še na začetku tretje medigre (167-172). Takšno teksturo, ki prevzame funkcijo "motiva", oziroma postane neločljiv del motivično-tematske vsebine, imenuje Berry motivic texture ali texture-motive. ${ }^{26}$ Glavna teksturna projekcija je akordsko homoritmična, sestavljena iz dveh akordskih plasti, ki sta harmonsko komplementarni (miksture), vendar intervalno nasprotnosmerni. ${ }^{27}$

Medigro med A' in C nadomešča pettaktni Uvod v tretjo temo (97-101, prim. 7). Zanimiv je zato, ker v njem doseže teksturna enostavnost ničelno točko. Je monofonska (s podvajanji v unisonu in oktavi). Še bolj zanimivo pa je dejstvo, da je to hkrati središče skladbe in mesto največje umiritve glasbenega toka. Dinamika je recesivni teksturi komplementarna, z zaporedjem padajočih vrednosti (ff-f-mf-p).

\footnotetext{
${ }^{25}$ Štiritaktji. imata enako teksturno podobo, ritem, melodične obrise in instrumentacijo, spremenjena so le intervalna razmerja in tonalno območje (harmonija). Enaki ostajata tudi dinamika in artikulacija.

${ }^{26}$ There are many times in music (perhaps especially that of the last hundred years) when materials are of such distinctive textural cast, and when the particular qualities of texture are so vital a factor in the identity and interest of thematicmotivic material, that it seems plausible to think and speak of texture as "motivic" - or of a specific 'texture-motive'. A thematic melody in voices interdependently doubled in 3rds, where this textural feature is a necessary and recurrent aspect of the material, would be properly conceived as "thematic texture" in an important sense. Ib., 254-255.

${ }^{27}$ Prvo izvajajo trobente, drugo pozavne in tuba.
} 
MUZIKOLOŠKI ZBORNIK • MUSICOLOGICAL ANNUAL XXXVIII Primer 7: Uvod v tretjo temo

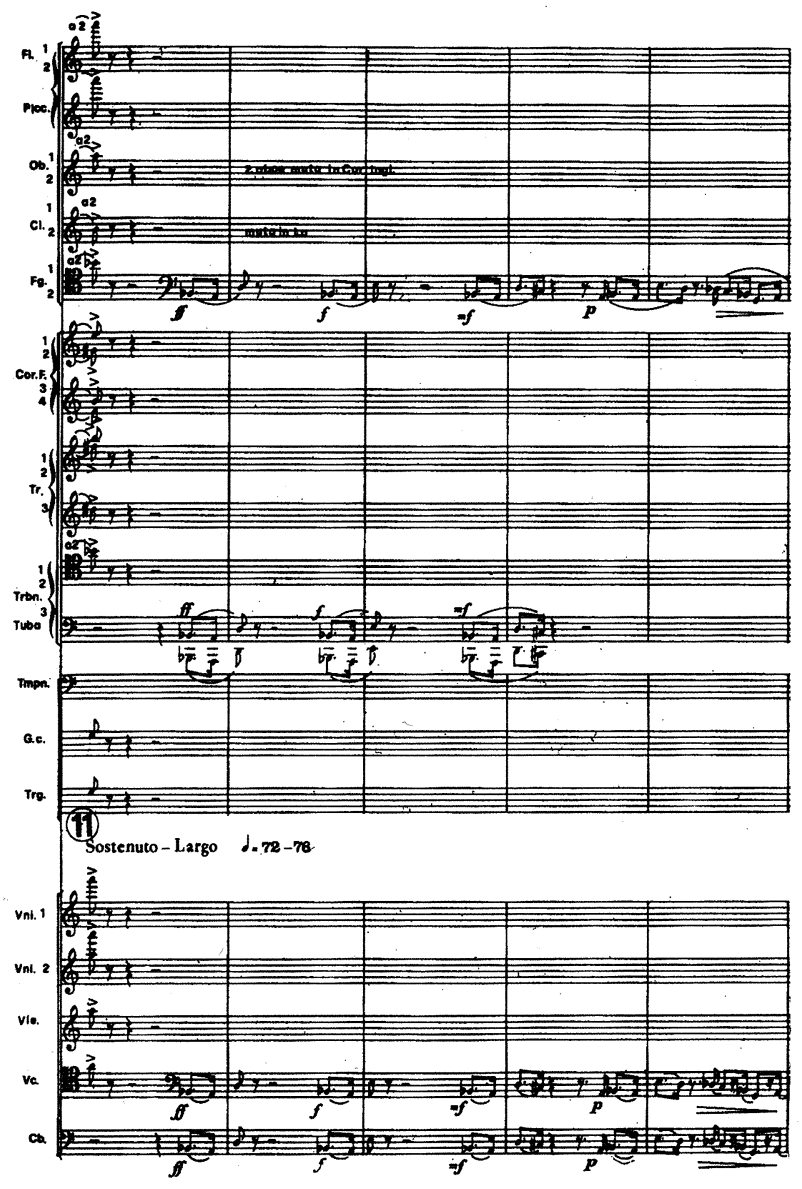

